\title{
Conversion of Lagenaria Siceraria peel to reduced graphene oxide doped with zinc oxide nanoparticles for supercapacitor applications
}

\author{
M.I. Pratheepa, M. Lawrence* \\ Department of Physics, St. Joseph's College (Autonomous), Tiruchirappalli, Tamil Nadu, India \\ *Corresponding author e-mail: jefflara1968@yahoo.co.in
}

\begin{abstract}
Graphene oxide was derived from Lagenaria Siceraria peel and the $\mathrm{ZnO}$ nanoparticles were synthesized using the green synthesis method. $\mathrm{Zn}_{1-\mathrm{x}} \mathrm{O}-\mathrm{rGO}_{\mathrm{x}}$ was synthesized with different concentrations $(x=0.1,0.2,0.3)$ that were referred as $S_{1}, S_{2}$, and $\mathrm{S}_{3}$, respectively. The rGO-ZnO nanoparticles have been characterized with XRD, DLS, zeta potential, FTIR, FT-Raman, UV, SEM, TEM, EDAX and mapping analysis. The charge storage, cycle stability of the $\mathrm{rGO}-\mathrm{ZnO}$ nanoparticles were explored using cyclic voltammetry. The highest specific capacitance for nanoparticles was determined to be 371 , 382 and $398 \mathrm{~F} / \mathrm{g}$ for $\mathrm{S}_{1}, \mathrm{~S}_{2}$, and $\mathrm{S}_{3}$ at the scan rate close to $10 \mathrm{mV} / \mathrm{s}$.
\end{abstract}

Keywords: natural Lagenaria Siceraria peel, rGO-ZnO, green synthesis, electrochemical property, supercapacitor applications.

https://doi.org/10.15407/spqeo24.02.115

PACS 81.05.ue, 84.60.Ve

Manuscript received 07.01.21; revised version received 24.03.21; accepted for publication 02.06.21; published online 16.06.21.

\section{Introduction}

With the gradual popularization of industrial automation technology and large-scale mechanized production, improper disposal of industrial wastes will not only waste resources but also pollute the environment. The energy shortage and environmental pollution are two focal issues of green development in today's society. There is an urgent need to explore a green chemical route to produce energy storage technology [1]. Supercapacitors (SC), owing to a high power density and long cycle life, are the most suitable source of energy for electric vehicles and portable devices [2-5]. Electric double-layer capacitors (EDLCs) are widely used because of their wide source of raw materials and long cycle life [6,7]. Carbon materials have a high surface area, chemical stability, electrical conductivity and a wide range of precursor sources, have aroused strong concern as electrode materials for supercapacitors $[1,5,8,9]$. Recently, renewable carbon materials derived from biomass have attracted extensive attention in application of electrode materials for supercapacitors [10-16]. For example, many investigators have researched wood, almond shell, amaranthus and peanut shell with high capacitance [17-22]. However, few works have concentrated on the recycling of industrial waste using electrode materials [23, 24].

Graphene is a flexible carbon sheet with a comparable structure to an individual layer of graphite. It has a single layer, bi-layer, and multilayer structure [25-27]. Graphene has high thermal conductivity, electrical conductivity, room temperature transporter versatility, quantum confinement [28], etc. The material has vowed its significant electronic properties, mechanical properties, predominant synthetic strength and high specific surface area [32]. Especially graphene is used for Li-ion batteries [29], pseudocapacitors [30], and electric double layer capacitors [31], etc. Formation of nanorings on graphene would increase the overall exposed surface area, since the inner edges of the nanorings along with graphene would also be available for catalytic activity [33]. These factors could be advantageous, since hybridization of a functional nanomaterial with high surface area, conducting, and lightweight graphene has been explored as an effective strategy for enhanced catalysis in energy conversion and storage [39].

Zinc oxide is a very promising material for supercapacitor application, it holds large capacitive properties. Graphene-based zinc oxide nanocomposites [37] have improved the electrical conductivity for good electrochemical performance. Contrasting to the other metal oxides, zinc oxide has a wide bandgap $3.37 \mathrm{eV}$. Various specialists have likewise orchestrated $\mathrm{ZnO}$ /graphene $[34,35]$ composites by different methodologies for a scope of uses. Many research articles have been contributed towards chemical approach [37,38], hence nowadays the green synthesis has acquired great attention due to its ease of productivity with high-performance capacitance and also non-hazardous [41]. 
In this work, reduced graphene oxide - zinc oxide (rGO-ZnO) synthesis has been reported, in which graphene oxide synthesized from pure green approach using Lagenaria Siceraria peel, and zinc oxide has been reduced from fresh Lagenaria Siceraria peel extract and delivered a specific capacitance of $398 \mathrm{~F} / \mathrm{g}$ and good cyclic stability from 300 to 1000 cycles, as compared to earlier reported [39] synthesized from supercritical carbon dioxide. When increasing the concentration of reduced graphene oxide, the good electrochemical performance has been achieved. The low cost and an effective electrode with non-hazardous material can be applicable in designing supercapacitors.

\section{Experimental}

\subsection{Materials}

Analytical reagent (AR) of zinc nitrate hexahydrate $\left(\mathrm{Zn}\left(\mathrm{NO}_{3}\right)_{2} \cdot 6 \mathrm{H}_{2} \mathrm{O}\right)$ was purchased from Sigma Aldrich with $98 \%$ purity, and Lagenaria Siceraria was collected from the vegetable market.

\subsection{Synthesis of cost-effective and eco-friendly graphene}

Lagenaria Siceraria peel was collected and washed thoroughly, then heated and dried at $1000{ }^{\circ} \mathrm{C}$, after that the substance was sonicated for $1 \mathrm{hr}$, washed and centrifuged, finally graphene precipitate was obtained. The graphene precipitate was dispersed in a water or methanol mixture, then $10 \mathrm{ml}$ of $30 \% \mathrm{H}_{2} \mathrm{O}_{2}$ added slowly and centrifuged with $\mathrm{HCl}$ for $1 \mathrm{hr}$ to obtain graphene oxide sheets. Finally, the thermal reduction has been taken to prepare reduced graphene oxide kept under $400{ }^{\circ} \mathrm{C}$ for $5 \mathrm{hrs}$.

\subsection{Synthesis of $\mathrm{rGO}-\mathrm{ZnO}$}

Pure zinc oxide nanoparticles were synthesized through a green approach by using fresh Lagenaria Siceraria peel as a reducing agent. Zinc nitrate hexahydrate was dissolved in deionized water and stirred well for $45 \mathrm{~min}$, and aqueous extract of Lagenaria Siceraria peel was added drop by drop, and the $\mathrm{pH}$ value of the solution was adjusted till 8 [43]. The rGO of three different molar concentrations $(x=0.1,0.2,0.3 \mathrm{M})$ was dispersed in $5 \mathrm{ml}$ of methanol and added to the above solution. The mixture was continuously stirred for $2 \mathrm{hrs}$. The precipitate was centrifuged and then washed with ethanol and water to remove the impurities present in it. The precipitate was kept under observation in the darkroom up to $12-15$ hours for ageing and dried at $100{ }^{\circ} \mathrm{C}$ by using a hot air oven. The dried powders were calcined at $300{ }^{\circ} \mathrm{C}$ for $5 \mathrm{hrs}$. Finally, rGO-ZnO nanoparticles obtained in three different concentrations were named as $\mathrm{S}_{1}, \mathrm{~S}_{2}$, and $\mathrm{S}_{3}$, respectively.

\subsection{Electrochemical measurements}

With a CHI 660D electrochemical workstation, the cyclic voltammetry, charge-discharge, and electrochemical impedance spectroscopy were performed. The rGO-ZnO nanoparticles were used as a modified operation electrode. A platinum plate and $\mathrm{Ag} / \mathrm{AgCl}$ electrode were used as the measuring and reference electrodes, respectively. $6 \mathrm{M} \mathrm{KOH}$ solution was used as an electrolyte for performing $\mathrm{CV}$ analysis at the room temperature. The EIS measurements were carried out over the frequency range from $0.1 \mathrm{~Hz}$ to $100 \mathrm{kHz}$ under the voltage $10 \mathrm{mV}$.

\subsection{Characterization techniques}

XRD (PANalytical, X'Pert-PRO MPD) was applied using $\mathrm{CuK}_{\alpha}$ radiation. Scanning electron microscope (SEM) and energy dispersive X-ray analysis (EDS) was obtained with a Zeiss ultra plus SEM apparatus. TEM images were obtained using Philips EM208 operating at the accelerating voltage close to $90 \mathrm{kV}$. Nano Plus Zeta/Nanoparticle analyzer instrument was used for dynamic light scattering (DLS). Jasco V530 UV-visible spectrophotometer was used to study optical properties. The Fourier transform infrared (FTIR) spectra were obtained using a Vertex 70v FTIR spectrophotometer (BRUKER, USA). Raman spectra were recorded using the LabRAM HR (UV) system with excitation by the line $532 \mathrm{~nm}$. Cyclic voltammetry (CV) was carried out with the electrochemistry workstation (CHI 660, China) by using a three-electrode system. A platinum plate and saturated $\mathrm{Ag} / \mathrm{AgCl}$ were used as the measuring and reference electrode, and $\mathrm{rGO}-\mathrm{ZnO}$ as a modified operation electrode.

\section{Results and discussions}

\subsection{Structural analysis}

Fig. 1 shows the XRD analysis of the as-synthesized rGO-ZnO, where the observed diffraction peaks at $31^{\circ}$, $33^{\circ}, 37^{\circ}$ and $47^{\circ}$ were related to the (100), (002), (101), and (102) planes of pure $\mathrm{ZnO}$ with a wurtzite hexagonal structure according to the JCPDS Card No 36-1451, and peaks at $25^{\circ}$ and $44^{\circ}$ were assigned to the (002) and (100) planes of reduced graphene oxide. The XRD analysis confirmed that the composition of $\mathrm{ZnO}$ with a wurtzite structure and pristine graphitic structure of rGO. Due to varying the concentration of rGO, we observed slight changes in the intensity of diffraction pattern as well as decrease in the crystallite size. The average crystallite

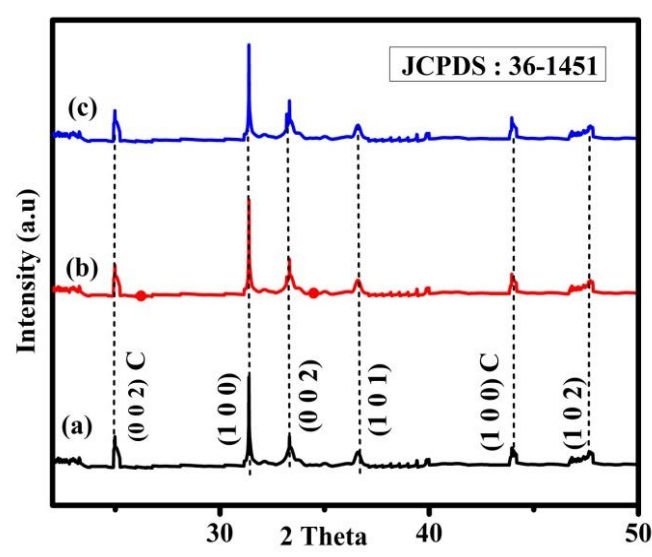

Fig. 1. XRD pattern of rGO-ZnO $\left(\mathrm{S}_{1}, \mathrm{~S}_{2}, \mathrm{~S}_{3}\right)$ nanoparticles. 
size of the nanoparticles was found to be 12.3, 8.9 and $6.5 \mathrm{~nm}$ for $S_{1}, S_{2}$ and $S_{3}$ samples, respectively.

The crystallite size was estimated using the DebyeScherrer formula

$D=\frac{K \lambda}{\beta \cos \theta}$,

where $\lambda$ is the wavelength of $\mathrm{X}$-rays, $\beta$ - full width at half maximum, $2 \theta$ - Bragg's diffraction angle.

By measuring the FWHM from X-ray diffraction pattern, the average crystallite size was calculated.

\subsection{Morphological and elemental analyses}

Fig. 2 shown (a)-(c) panels indicate SEM micrographs, (d)-(f) for TEM images, (g)-(i) for EDAX spectrum, and (j), (k) for EDAX mapping of the rGO-ZnO nanoparticles $\left(S_{1}, S_{2}\right.$, and $\left.S_{3}\right)$. It can be seen that the numerous $\mathrm{ZnO}$ nanoflakes are incorporated into the reduced graphene nanosheets. The $\mathrm{ZnO}$ nanoparticles were grown uniformly on the graphene layer with a porous structure.

The particle size for all the three samples was found to be $6.1,4.8$, and $3 \mathrm{~nm}$ for $\mathrm{S}_{1}, \mathrm{~S}_{2}$, and $\mathrm{S}_{3}$, respectively. The TEM images show the $\mathrm{ZnO}$ particles of the spherical

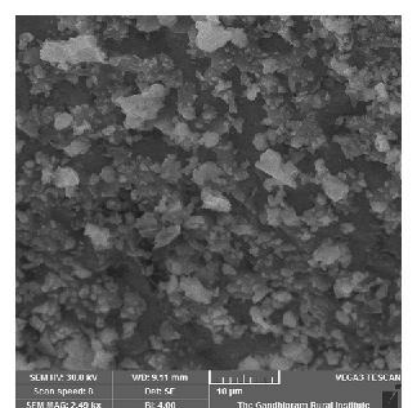

a)

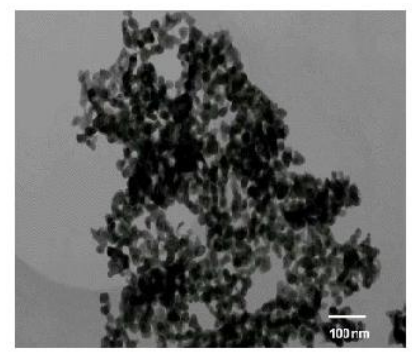

d)

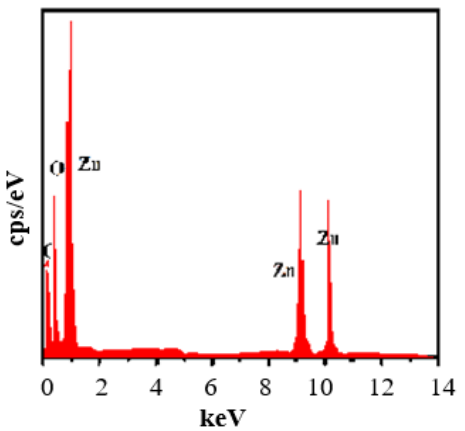

g)

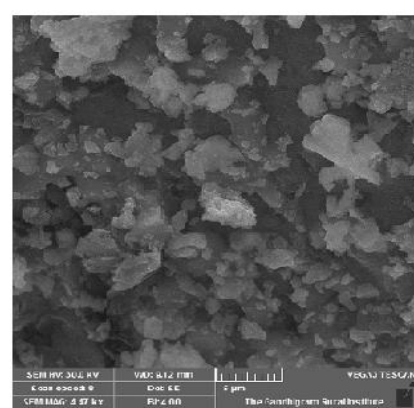

b)

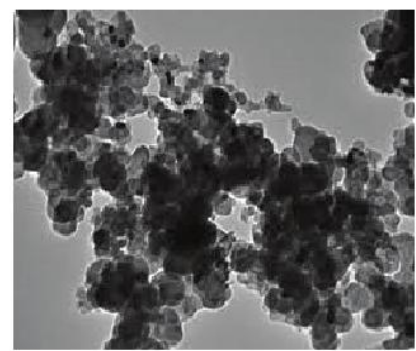

e)

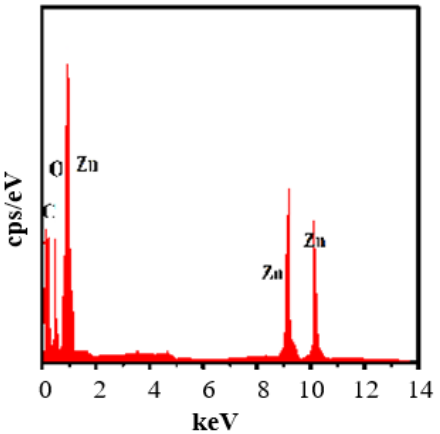

h)

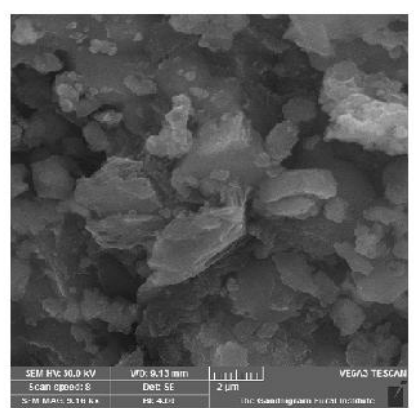

c)

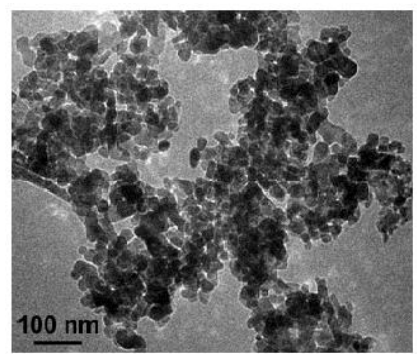

f)

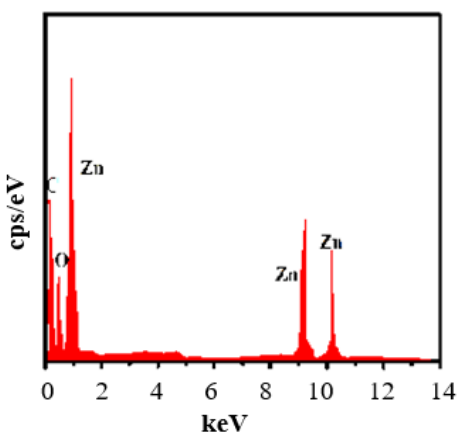

i)

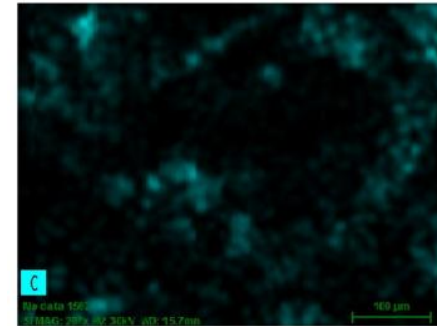

j)

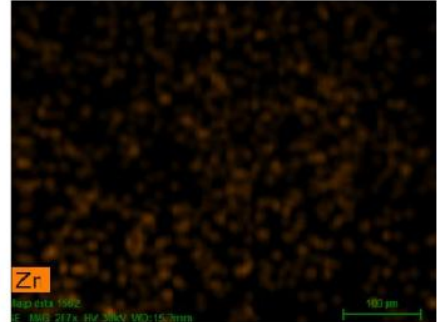

k)

Fig. 2. (a)-(c) SEM micrographs, (d)-(f) TEM images, (g)-(i) EDAX spectra, and (j), (k) EDAX mapping for rGO-ZnO $\left(\mathrm{S}_{1}, \mathrm{~S}_{2}, \mathrm{~S}_{3}\right)$ nanoparticles.

Pratheepa M.I., Lawrence M. Conversion of Lagenaria Siceraria peel to reduced graphene ... 
shape, which are evenly spread into rGO sheets. The elemental and mapping analysis affirms that the samples are around the ostensible composition of carbon, zinc, and oxide for all the three doping concentrations.

\subsection{Dynamic light scattering analysis}

Fig. 3 demonstrates the particle size distribution of the synthesized rGO-ZnO nanoparticles using dynamic light scattering (DLS) measurements. The attained result gives a hydrodynamic average diameter of $3.4 \mathrm{~nm}$. The DLS measurement gives the average crystallite size 5.4, 4.2 and $3.2 \mathrm{~nm}$ for $S_{1}, S_{2}$ and $S_{3}$, respectively. Hence, the particle size of rGO-ZnO nanoparticles calculated from SEM analysis was reconfirmed.

\subsection{Zeta potential}

The zeta potential of the $\mathrm{rGO} / \mathrm{ZnO}$ nanoparticles was investigated for all the three samples to measure the surface charge of the nanoparticles. The variation of concentration in rGO-ZnO nanoparticles versus zeta potential has shown in Fig. 4, which implies that

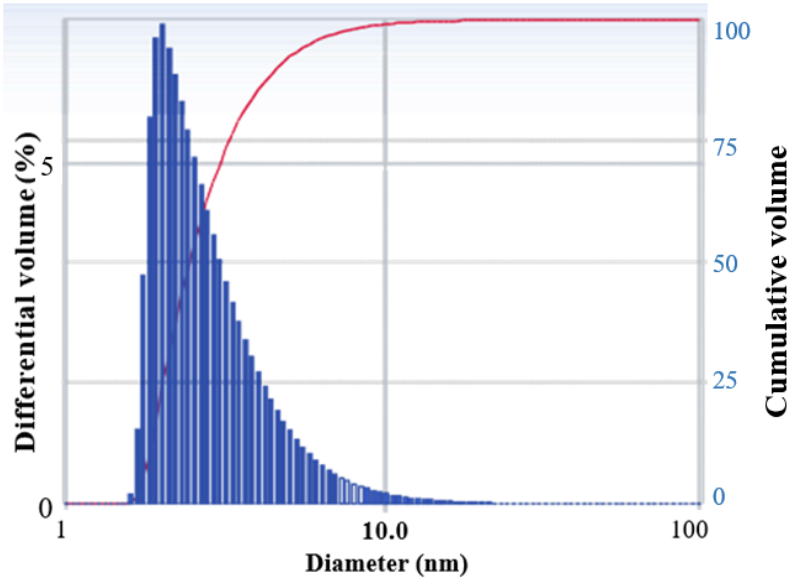

Fig. 3. Size distribution of rGO-ZnO nanoparticles using the dynamic light scattering measurement.

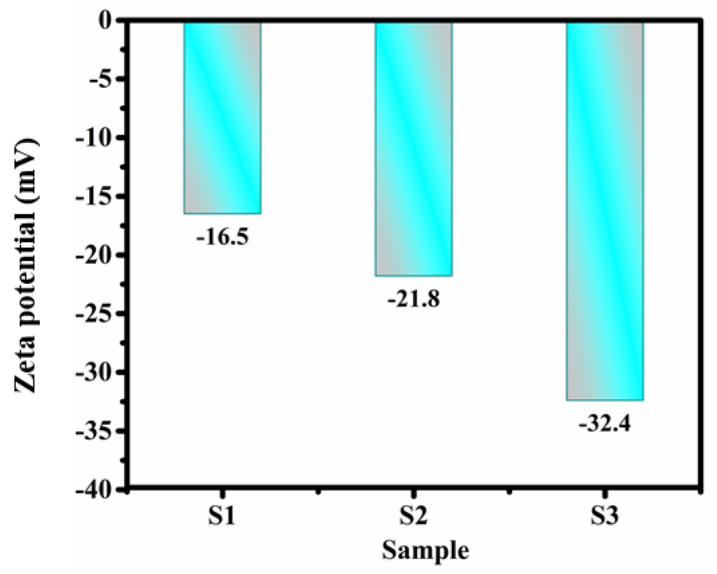

Fig. 4. Zeta potential of rGO-ZnO $\left(\mathrm{S}_{1}, \mathrm{~S}_{2}, \mathrm{~S}_{3}\right)$ nanoparticles.

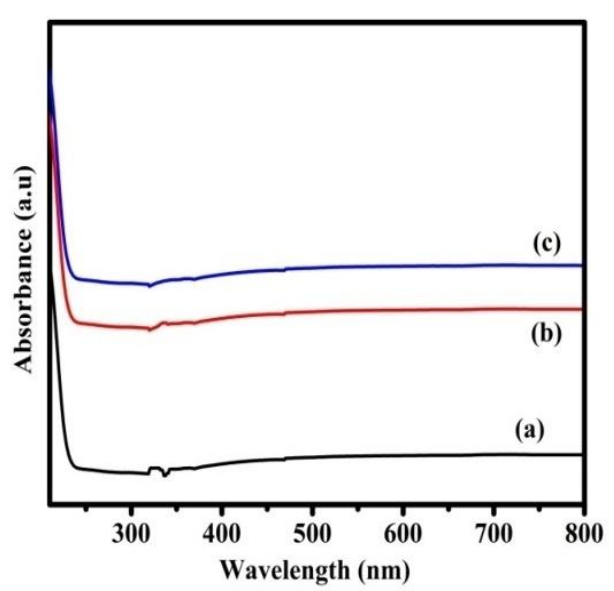

Fig. 5. Absorbance spectra of $\mathrm{rGO}-\mathrm{ZnO}\left(\mathrm{S}_{1}, \mathrm{~S}_{2}, \mathrm{~S}_{3}\right)$ nanoparticles.

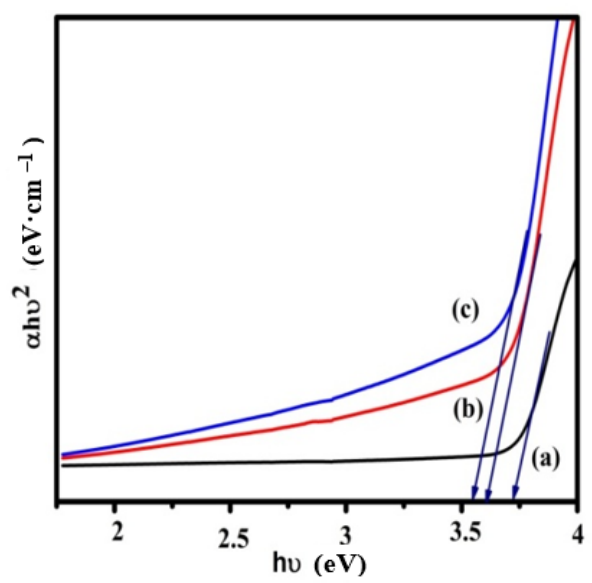

Fig. 6. Tauc's plot of rGO-ZnO $\left(\mathrm{S}_{1}, \mathrm{~S}_{2}, \mathrm{~S}_{3}\right)$ nanoparticles.

the particles contain negative charge $-16.5 \mathrm{mV}\left(\mathrm{S}_{1}\right)$, $-21.8 \mathrm{mV}\left(\mathrm{S}_{2}\right)$, and $-32.4 \mathrm{mV}\left(\mathrm{S}_{3}\right)$ as it increases with concentration indicating the electrostatic repulsive forces were responsible for the decrease in particle size of the nanoparticles, and also the particles are very stable at room temperature.

\subsection{Optical analysis}

Fig. 5 presents the typical UV-vis absorption spectra of rGO-ZnO. The spectrum was traced within the wavelength range between 200 and $800 \mathrm{~nm}$. The absorption peaks are located at 325, 335 and $342 \mathrm{~nm}$ for $\mathrm{S}_{1}, \mathrm{~S}_{2}$ and $\mathrm{S}_{3}$, respectively. The UV-vis absorption spectra of bulk $\mathrm{ZnO}$ was reported to appear at $375 \mathrm{~nm}$. It shows a blue-shift, due to the particle size in the nanometer range below $15 \mathrm{~nm}$.

The optical band gap values are shown in Fig. 6, and it was extrapolated from the linear part to the $x$-axis. They are as follows: $3.7,3.62$ and $3.58 \mathrm{eV}$ in accord with Tauc's plot. 


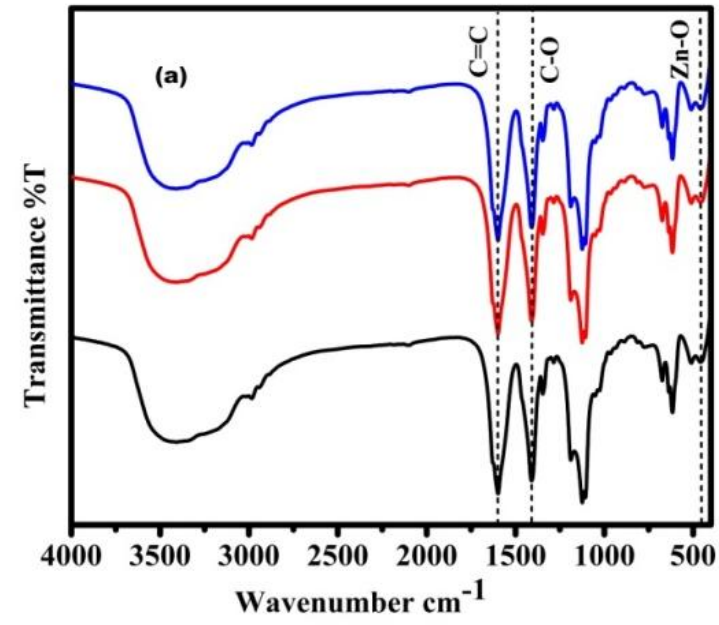

Fig. 7. FTIR spectrum of rGO-ZnO $\left(\mathrm{S}_{1}, \mathrm{~S}_{2}, \mathrm{~S}_{3}\right)$ nanoparticles.

\subsection{FTIR and FT-Raman analyses}

FTIR spectroscopy gives the additional evidence of the functional groups in $\mathrm{rGO}-\mathrm{ZnO}$ nanoparticles, and the respective spectra are shown in Fig. 7. The peaks of GO at 1598 and $1409 \mathrm{~cm}^{-1}$ are ascribed to $\mathrm{C}-\mathrm{O}$ stretching vibrations of $\mathrm{COOH}$ groups. Moreover, the band at $1124 \mathrm{~cm}^{-1}$ for $\mathrm{C}-\mathrm{O}$ stretching vibrations is combined with the $\mathrm{C}-\mathrm{OH}$ bending ones. The peak around $1284 \mathrm{~cm}^{-1}$ is attributed to the $\mathrm{C}-\mathrm{OH}$ group. The biomolecules present in the peel extract are also confirmed. The peak at $458 \mathrm{~cm}^{-1}$ is attributed to the stretching mode of $\mathrm{Zn}-\mathrm{O}$, which can affirm the presence of $\mathrm{rGO}-\mathrm{ZnO}$ nanoparticles.

Fig. 8 demonstrates the Raman spectra of the prepared nanoparticles within the range 1000 to $2000 \mathrm{~cm}^{-1}$. A Raman spectrum provides the essential characterization analysis for graphene-based materials. The spectrum reveals the presence of single-, bi- \& multilayer graphene or graphene oxide materials. It can be seen that the $\mathrm{G}$ band at $1590 \mathrm{~cm}^{-1}$ and $\mathrm{D}$ band at $1328 \mathrm{~cm}^{-1}$ confirm that the prepared material is singlelayer reduced graphene oxide for all the three samples.

\subsection{Electrochemical performance and impedance spectroscopy}

The effectuation of synthesized materials was analyzed using the cyclic voltammetry, which gave the CV curve, galvanostatic charge-discharge curve and enabled to give the results of electrochemical impedance spectroscopy. Fig. 9a clearly shows the $\mathrm{CV}$ curve of the rGO-ZnO electrode of Faradaic redox peaks, which has the potential window ranging between -1.5 to $1.5 \mathrm{~V}$. The cyclic voltammetry of $\mathrm{rGO}-\mathrm{ZnO}$ shows a narrow rectangle curve, indicates the absence of electrochemical activity and a small capacitance due to the highest charge transfer and conduction in the reduced graphene oxide -

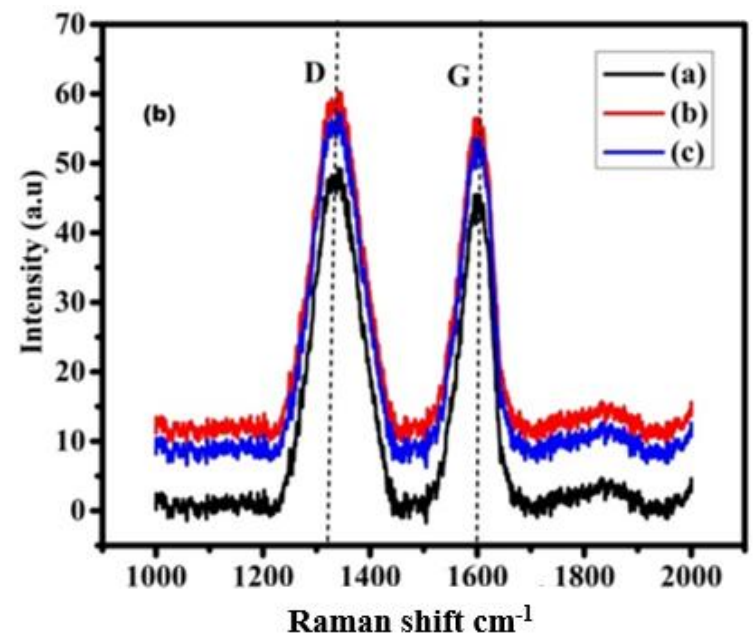

Fig. 8. FT-Raman spectra of rGO-ZnO $\left(\mathrm{S}_{1}, \mathrm{~S}_{2}, \mathrm{~S}_{3}\right)$ nanoparticles.

zinc oxide composite [42]. These outcomes additionally testify that the large capacitance of $\mathrm{rGO}-\mathrm{ZnO}$ arise from the pseudocapacitance of the electrochemically active $\mathrm{ZnO}$ nanoflakes. The specific capacitance can be calculated using the following formula:

$C_{s p}=\frac{I d v}{2 m v \Delta V}$

where $C_{s p}$ is the specific capacitance $(\mathrm{F} / \mathrm{g}), I d v-$ integrated area, $m$ - mass of active material in the electrode $(\mathrm{g}), v$ - scan rate $(\mathrm{mV} / \mathrm{s}), \Delta V-$ potential window (V).

To estimate the electrochemical capacitance of the $\mathrm{S}_{1}, \mathrm{~S}_{2}, \mathrm{~S}_{3}$, the galvanostatic charge-discharge curves were presented in Fig. 9b. The linear triangular shape inherent to a double-layer capacitor shows electrochemical adsorption of the electrode and electrolyte. The specific capacitance of the synthesized nanoparticles at different scan rates has appeared in Fig. 9c.

It may be very well seen that the specific capacitance gradually decreases with increasing the current density, which might be ascribed to the diffusion of electrolyte ions, which is confined because of the time constraint at high current density. The specific capacitance of rGO-ZnO nanoparticles was found to be 371,382 and $398 \mathrm{~F} / \mathrm{g}$ for $\mathrm{S}_{1}, \mathrm{~S}_{2}$, and $\mathrm{S}_{3}$ at the scan rate $10 \mathrm{mV} \cdot \mathrm{s}^{-1}$. With the increase in concentration, the capacitance also showed a significant increase, thus we can say that $\mathrm{S}_{3} \quad(x=0.3)$ has shown a good electrochemical performance. Since the synthesized material shows the specific capacitance below $400 \mathrm{~F} / \mathrm{g}$, it can act as an electrode material for supercapacitor applications. In future, we can enhance the efficiency by adding some other metal composites. Hence, with increasing the concentration the material can give a good performance in supercapacitor application. 


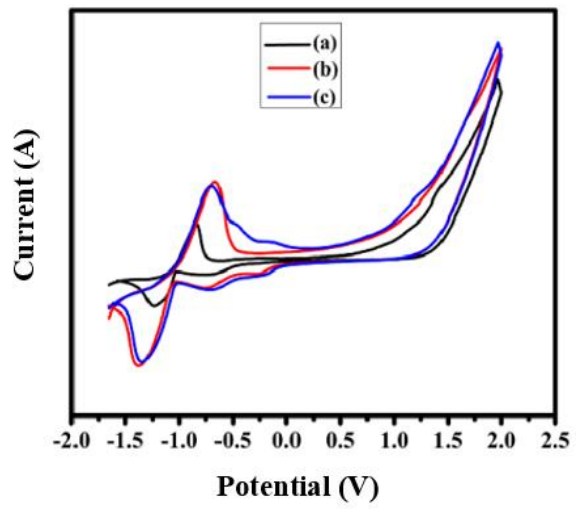

a)

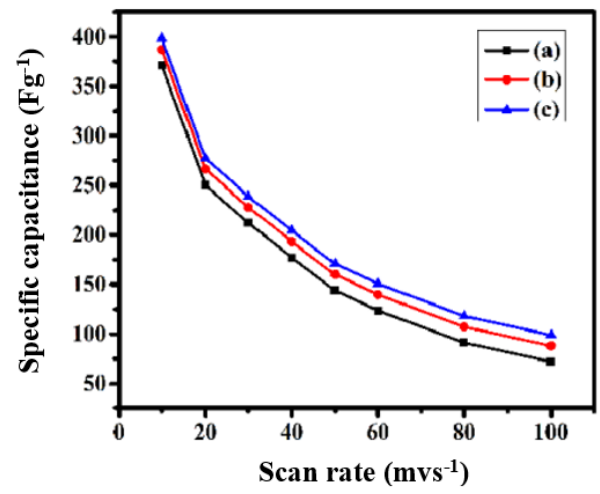

c)

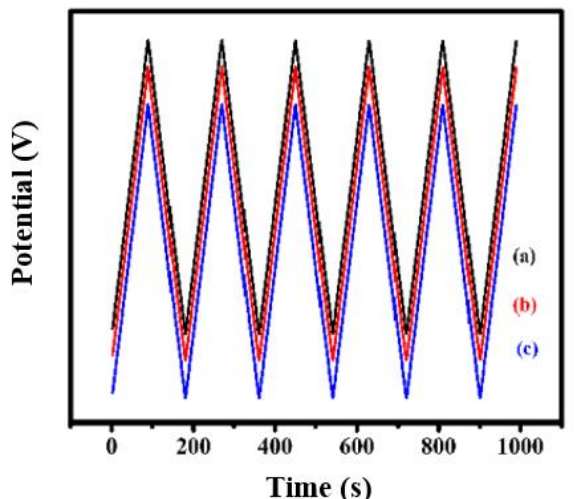

b)

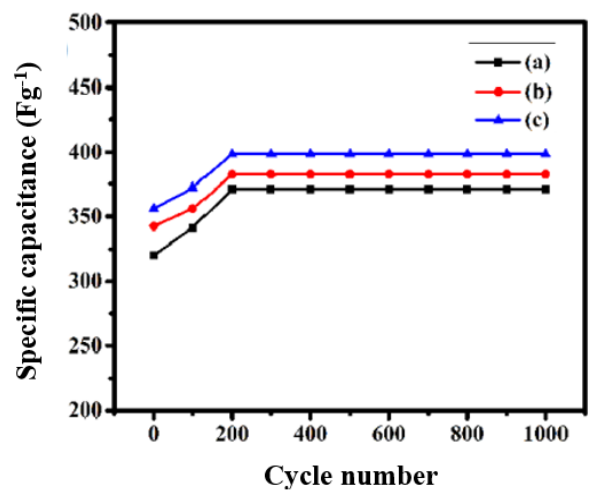

d)

Fig. 9. (a) CV curve, (b) galvanostatic charge-discharge, (c) plots of the scan rate $v s$ specific capacitance, (d) plots of cycle number $v s$ specific capacitance of $\mathrm{rGO}-\mathrm{ZnO}\left(\mathrm{S}_{1}, \mathrm{~S}_{2}, \mathrm{~S}_{3}\right)$ nanoparticles.

Investigating the cycle stability of the synthesized rGO-ZnO electrode is the most significant for supercapacitor applications. In Fig. 9d, the columbic efficiency of the rGO-ZnO electrode has been analyzed. Even after 1000 cycles, it reveals the columbic efficiency of about $92 \%$, which results in the excellent cyclic stability and columbic efficiency of rGO-ZnO that may be ascribed to its high specific surface area and porous bulk. At a current density of $10 \mathrm{Ag}^{-1}$, the specific capacitance of $\mathrm{rGO}-\mathrm{ZnO}$ electrode gradually increased to $10 \%$ during the first 200 cycles, due to the insertion

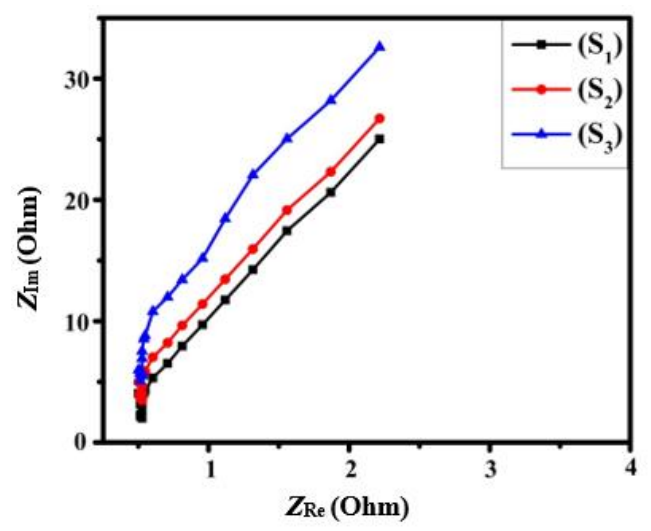

Fig. 10. Nyquist plot of rGO-ZnO $\left(\mathrm{S}_{1}, \mathrm{~S}_{2}, \mathrm{~S}_{3}\right)$ nanoparticles. or exertion of the electrolyte ion and the specific capacitance remains constant between 300 to 1000 cycles, which indicates that the material has good cyclic stability. As an outcome, the determined high stability and reversibility of the rGO-ZnO electrode are obvious.

The impedance spectroscopy is a dynamic technique for analyzing the capacitive behavior of electrode materials. Fig. 10 demonstrates the Nyquist plots of $\mathrm{rGO}-\mathrm{ZnO}$ at frequencies within the range of $100 \mathrm{kHz}$ to $10 \mathrm{MHz}$ at an open circuit potential. The rGO-ZnO nanoparticles that uncover the predominant electrical conductivity of this material accommodate the ion and electron transfer in the electrode and electrolyte. Thereof, we can calculate the ESR value in the highfrequency region, the $\mathrm{X}$-intercept at the real axis is observed to be $0.6 \mathrm{Ohm}$ for $\mathrm{S}_{1}, \mathrm{~S}_{2}, \mathrm{~S}_{3}$, representing a low equivalent series resistance and indicates the good conducting behavior. This illustrates the rGO-ZnO nanoparticles having good electrochemical properties.

\section{Conclusion}

The reduced graphene oxide has been synthesized from Lagenaria Siceraria peel for eco-friendly supercapacitor application. The attributed XRD peaks with a high intensity affirm the pronounced crystalline structure of rGO$\mathrm{ZnO}$ nanoparticles, and the average crystallite size has been decreased when increasing the concentration of rGO. 
SEM, TEM, EDAX, and mapping confirm that the synthesized rGO-ZnO nanoparticles are well-defined nanostructures and clearly show incorporation of the $\mathrm{ZnO}$ particles in $\mathrm{rGO}$ sheets. The functional groups present in the FTIR spectrum attributes formation of rGO-ZnO. Raman spectroscopy indicates the presence of $\mathrm{G}$ and $\mathrm{D}$ bands. The observed absorption band enables to suggest that the synthesized $\mathrm{rGO}-\mathrm{ZnO}$ exhibit quantum confinement effect. The above estimate of the direct bandgap is $3.7,3.62$ and $3.58 \mathrm{eV}$ of the synthesized nanoparticles. It exhibits a very high charge storage capacity with a specific capacitance of 371,382 and $398 \mathrm{~F} / \mathrm{g}$ for $\mathrm{S}_{1}, \mathrm{~S}_{2}$, and $\mathrm{S}_{3}$ at the scan rate of $10 \mathrm{mV} / \mathrm{s}$. On the whole, $\mathrm{S}_{3}$ has the highest specific capacitance, because the particle size is smaller. This high supercapacitor performance can be attributed to a specific nature of microporosity combined with a high surface area, which is due to the uniform distribution of the minerals present in the Lagenaria Siceraria peel. The phenomenal electrochemical capacitive properties make the synthesized rGO-ZnO nanoparticles a vowing electrode material for high-performance supercapacitors, especially from the green synthesis as compared to the chemical one. In future, advanced optimization of this material can lead to a great electrochemical application.

\section{References}

1. Chen F., Zhou W.J., Yao H.F. et al. Self-assembly of $\mathrm{NiO}$ nanoparticles in lignin-derived mesoporous carbons for supercapacitor applications. Green Chem. 2013. 15, No 11. P. 3057-3063. https://doi.org/10.1039/C3GC41080C.

2. Simon P., Gogotsi Y. Capacitive energy storage in nanostructured carbon-electrolyte systems. Accounts Chem. Res. 2013. 46, No 5. P. 1094-1103. https://doi.org/10.1021/AR200306B.

3. Wei J.S., Ding C., Zhang P. et al. Robust negative electrode materials derived from carbon dots and porous hydrogels for high-performance hybrid supercapacitors. Adv Mater. 2019. 31. P. 5. https://doi.org/10.1002/adma.201806197.

4. Wang Y.G., Xia Y.Y. Recent progress in supercapacitors: From materials design to system construction. Adv Mater. 2013. 25, No 37. P. 53365342. https://doi.org/10.1002/adma.201301932.

5. Qian W., Chen Z.Q., Cottingham S. et al. Surfactant-free hybridization of transition metal oxide nanoparticles with conductive graphene for high-performance supercapacitor. Green Chem. 2012. 14, No 2. P. 371-377.

https://doi.org/10.1039/C1GC16134B.

6. Hu X., Nango K., Bao L. et al. High yields of solid carbonaceous materials from biomass. Green Chem. 2019. 21, No 5. P. 1128-1140. https://doi.org/10.1039/C8GC03153C.

7. Simon P., Gogotsi Y., Dunn B. Where Do Batteries End and Supercapacitors Begin? Science. 2014. 343 (6176). P. 1210-1211. https://doi.org/10.1126/science.1249625.
8. Beguin F., Presser V., Balducci A., Frackowiak E. Carbons and electrolytes for advanced supercapacitors. Adv. Mater. 2014. 26, No 14. P. 2219 2251. https://doi.org/10.1002/adma.201304137.

9. Zhai Y.P., Dou Y.Q., Zhao D.Y. et al. Carbon materials for chemical capacitive energy storage. Adv. Mater. 2011. 23, No 42. P. 4828-4850. https://doi.org/10.1002/adma.201100984.

10. Zhang J.T., Jiang J.W., Li H.L., Zhao X.S. A highperformance asymmetric supercapacitor fabricated with graphene-based electrodes. Energy Environ. Sci. 2011. 4, No 10. P. 4009-4015. https://doi.org/10.1039/C1EE01354H.

11. Zhu Y.W., Murali S., Stoller M.D. et al. Carbonbased supercapacitors produced by activation of graphene. Science. 2011. 6037. P. 1537-1541. https://doi.org/10.1126/science.1200770.

12. Pech D., Brunet M., Durou H. et al. Ultrahighpower micrometer-sized supercapacitors based on onion-like carbon. Nature Nanotech. 2010. 5, No 9. P. 651-654. https://doi.org/10.1038/nnano.2010.162.

13. Yao B., Yuan L.Y., Xiao X. et al. Paper-based solid-state supercapacitors with pencil-drawing graphite/polyaniline networks hybrid electrodes. Nano Energy. 2013. 2, No 6. P. 1071-1078. https://doi.org/10.1016/j.nanoen.2013.09.002.

14. Yu Z.Y., Chen L.F., Song L.T. et al. Free-standing boron and oxygen co-doped carbon nanofiber films for large volumetric capacitance and high rate capability supercapacitors. Nano Energy. 2015. 15. P. 235243. https://doi.org/10.1016/j.nanoen.2015.04.017.

15. Qie L., Chen W.M., Xu H.H. et al. Synthesis of functionalized 3D hierarchical porous carbon for high-performance supercapacitors. Energy Environ. Sci. 2013. 6, No 8. P. 2497-2504. https://doi.org/10.1039/C3EE41638K.

16. Li Y.J., Wang G.L., Wei T., Fan Z.J., Yan P. Nitrogen and sulfur co-doped porous carbon nanosheets derived from willow catkin for supercapacitors. Nano Energy. 2016. 19. P. 165175. https://doi.org/10.1016/j.nanoen.2015.10.038.

17. Wang Y.M., Lin X.J., Liu T. et al. Wood-derived hierarchically porous electrodes for highperformance all-solid-state supercapacitors. Adv. Funct. Mater. 2018. 28. P. 52. https://doi.org/10.1002/adfm.201806207.

18. Wu C., Yang S.R., Cai J.J., Zhang Q.B., Zhu Y., Zhang K.L. Activated microporous carbon derived from almond shells for high energy density asymmetric supercapacitors. ACS Appl. Mater. Interfaces. 2016. 8, No 24. P. 15288-15296. https://doi.org/10.1021/acsami.6b02942.

19. Gao S. Y., Geng K.R., Liu H.Y. et al. Transforming organic-rich amaranthus waste into nitrogen-doped carbon with superior performance of the oxygen reduction reaction. Energy Environ. Sci. 2015. 8, No 1. P. 221-229. https://doi.org/10.1039/C4EE02087A. 
20. Wang M.Q., Zhou J., Wu S.J., Wang H., Yang W. Green synthesis of capacitive carbon derived from Platanus catkins with high energy density. $J$. Mater. Sci.: Mater. Electron. 2019. 30, No 4. P. 4184-4195. https://doi.org/10.1007/s10854-01900710-9.

21. Qiang L.L., Hu Z.A., Li Z.M. et al. Hierarchical porous biomass carbon derived from cypress coats for high energy supercapacitors. J. Mater. Sci.: Mater. Electron. 2019. 30, No 8. P. 7324-7336. https://doi.org/10.1007/s10854-019-01045-1.

22. Chen C.T., Wang S., Peng Z.G., Ao G.H. Hierarchical porous architecture on $\mathrm{Ni}$ foam created via an oxidization-reduction process and its application for supercapacitor. J. Mater. Sci.: Mater. Electron. 2019. 30, No 12. P. 11231-11238. https://doi.org/10.1007/s10854-019-01468-w.

23. Xing P., Ma B.Z., Wang C.Y., Wang L., Chen Y.Q. A simple and effective process for recycling zinc-rich paint residue. Waste Management. 2018. 76. P. 234-241.

https://doi.org/10.1016/j.wasman.2018.03.018.

24. Min J.K., Zhang S., Li J.X. et al. From polystyrene waste to porous carbon flake and potential application in supercapacitor. Waste Management. 2019. 85. P. 333-340.

https://doi.org/10.1016/j.wasman.2019.01.002.

25. Mingo N., Broido D.A. Carbon nanotube ballistic thermal conductance and its limits. Phys. Rev. Lett. 2005. 95. P. 096105.

https://doi.org/10.1103/PhysRevLett.95.096105.

26. Novoselov K.S., Geim A.K., Morozov S.V. et al. Two-dimensional gas of massless Dirac fermions in graphene. Nature. 2005. 438. P. 197-200. https://doi.org/10.1038/nature04233.

27. Berger C., Song Z., Li T. et al. Ultrathin epitaxial graphite: 2D electron gas properties and a route toward graphene-based nanoelectronics, J. Phys. Chem. B. 2004. 108. P. 19912. https://doi.org/10.1021/jp040650f.

28. Wessells C., Ruffo R., Huggins R.A. \& Cui Y. Investigation of the electrochemical stability of aqueous electrolyte for lithium battery applications. Electrochem. Solid-State Lett. 2010. 13, No 5. P. A59. https://doi.org/10.1149/1.3329652.

29. de Souza R.A., Arashiro E., Golveia H., Lassali T.A.F. Pseudocapacitive behavior of $\mathrm{Ti} / \mathrm{RhO}_{\mathrm{x}}+$ $\mathrm{Co}_{3} \mathrm{O}_{4}$ electrodes in acidic medium: Application to supercapacitor development. Electrochim. Acta. 2004. 49. P. 2015-2023.

https://doi.org/10.1016/j.electacta.2003.12.031.

30. Qu D and Shi H. Studies of activated carbons used in double-layer capacitors. J. Power Sources. 1998. 74. P. 99-107. https://doi.org/10.1016/S03787753(98)00038-X.

31. Chu F.-H., Huang C.-W., Hsin C.-L. et al. Wellaligned $\mathrm{ZnO}$ nanowires with excellent field emission and photocatalytic properties. Nanoscale. 2012. 4, No 5. P. 1471-1475. https://doi.org/10.1039/c1nr10796h.
32. Vivekchand S.R.C., Rout C.S., Subrahmanyam K.S. et al. Graphene-based electrochemical supercapacitors. J. Chem. Sci. 2008. 120. P. 9-13. https://doi.org/10.1007/s12039-008-0002-7.

33. Liu Q., Liu Z.F., Zhang X.Y. et al. Organic photovoltaic cells based on an acceptor of soluble grapheme. Appl. Phys. Lett. 2008. 92. P. 223303. https://doi.org/10.1063/1.2938865.

34. Lu T., Zhang Y.P., Li H.B., Pan L.K., Li Y.L., Sun Z. Electrochemical behaviors of graphene$\mathrm{ZnO}$, and graphene- $\mathrm{SnO}_{2}$ composite films for supercapacitors. Electrochim. Acta. 2010. 55. P. 4170-4173. https://doi.org/10.1016/j.electacta.2010.02.095.

35. Li B., Cao H. ZnO-graphene composite with enhanced performance for the removal of dye from water. J. Mater. Chem. 2011. 21. P. 3346-3349. https://doi.org/10.1039/C0JM03253K.

36. Wu J., Shen X., Jiang L., Wang K., Chen K. Solvothermal synthesis and characterization of sandwich-like GO/ZnO composites. Appl. Surf. Sci. 2010. 256. P. 2826-2830.

https://doi.org/10.1016/j.apsusc.2009.11.034.

37. Baby T.T., Ramaprabhu S. Investigation of thermal and electrical conductivity of graphene-based nanofluids. J. Appl. Phys. 2010. 108. P. 124308. https://doi.org/10.1063/1.3516289.

38. Momeni M.M., Ghayeb Y. \& Menati M. Fabrication, characterization and photoelectrochemical properties of cuprous oxide-reduced graphene oxide photocatalysts for hydrogen generation. J. Mater. Sci.: Mater. Electron. 2018. 29. P. 4136-4146. https://doi.org/10.1007/s10854-017-8358-4.

39. Haldorai Y., Voit W., Shim J.J. Nano ZnO-reduced graphene oxide composite for high performance supercapacitor: Green synthesis in supercritical fluid. Electrochim. Acta. 2014. 120. P. 65. https://doi.org/10.1016/j.electacta.2013.12.063.

40. Wang J., Gao Z., Li Z. et al. Green synthesis of graphene nanosheets/ZnO composites and electrochemical properties. J. Solid State Chem. 2011. 184. P. 1421.

https://doi.org/10.1016/j.jssc.2011.03.006.

41. Ye X., Zhu Y., Tang Z., Wan Z. and Jia C. In-situ chemical reduction produced graphene paper for flexible supercapacitors with impressive capacitive performance. J. Power Sources. 2017. 360. P. 48. https://doi.org/10.1016/j.jpowsour.2017.05.103.

42. Pratheepa M.I., Lawrence M. Synthesis of pure, $\mathrm{Cu}$ and $\mathrm{Zn}$ doped $\mathrm{CdO}$ nanoparticles by coprecipitation method for supercapacitor applications. Vacuum. 2019. 162. P. 208. https://doi.org/10.1016/j.vacuum.2019.01.042.

43. Pratheepa M.I. \& Lawrence M. Eco-friendly approach in supercapacitor application: $\mathrm{CuZnCdO}$ nanosphere decorated in reduced graphene oxide nanosheets. SN Appl. Sci. 2020. 2. P. 318. https://doi.org/10.1007/s42452-020-2123-7. 


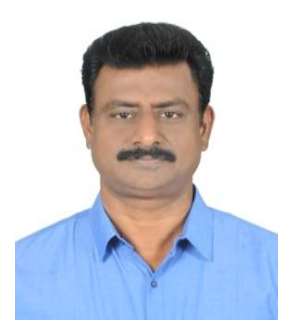

M. Lawrence, $\mathrm{PhD}$, Assistant Professor of St. Joseph's college, Tamil Nadu, India, received his PhD degree in Physics in 2013. He published more than ten papers and is much interested in the area of crystal growth and nanomaterials.

ORCID ID: https://orcid.org/00000003-4570-5592.

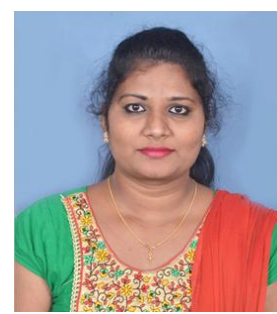

M. Iniya Pratheepa, $\mathrm{PhD}$ in Physics, Researcher at the Department of Physics, St. Joseph's college, Tamil Nadu, India, for supercapacitor applications. Author of more than five publications. Her research interests include materials science, nanomaterials, biomaterials, manufacture of single crystals and researching their properties. E-mail: iniyapratheepa11@gmail.com;

ORCID ID: https://orcid.org/0000-0001-5505-1604.

\section{Перетворення тонкого шару Lagenaria Siceraria у відновлені наночастинки оксиду графену, леговані оксидом цинку, для створення суперконденсаторів}

\section{M.I. Pratheepa, M. Lawrence}

Анотація. Оксид графену отримано із тонкого шару Lagenaria Siceraria и наночастинок ZnO, синтезованих методом зеленого синтезу. $\mathrm{Zn}_{1-\mathrm{x}} \mathrm{O}-\mathrm{rGO}_{\mathrm{x}}$ синтезовано с різними концентраціями $(x=0,1,0,2,0,3)$, які позначено $\mathrm{S}_{1}, \mathrm{~S}_{2}$ та $\mathrm{S}_{3}$ відповідно. Наночастинки $\mathrm{rGO}-\mathrm{ZnO}$ були охарактеризовані 3 використанням таких методів: рентгеноструктурний аналіз, динамічне розсіювання світла, дзета-потенціал, ІЧ-спектрометрія 3 Фур'є перетворенням, комбінаційне розсіювання світла 3 Фур'є перетворенням, УФ, скануюча електронна мікроскопія, просвічуюча електронна мікроскопія, енергодисперсійна рентгенівська спектроскопія та аналіз картування. Зберігання заряду, стабільність циклу наночастинок rGO-ZnO досліджували за допомогою циклічної вольтамперометрії. Найвища питома ємність для наночастинок становила 371,382 та 398 Ф/г відповідно для $\mathrm{S}_{1}, \mathrm{~S}_{2}$ та $\mathrm{S}_{3}$ при швидкості сканування $10 \mathrm{mB} / \mathrm{c}$.

Ключові слова: натуральний тонкий шар Lagenaria Siceraria, rGO-ZnO, зелений синтез, електрохімічні властивості, суперконденсатори. 